he went home in good health and in November resumed work. Since the operation he had gained $14 \mathrm{lb}$. in weight.

The tumour removed was almost entirely enchondromatous and very hard. Some soft myxomatous growth was found in front, where the crico-thyroid was perforated. The tumour sprang from the posterior part of the cricoid cartilage, completely filling it and also infiltrating and enlarging the sides of the cartilage itself. In the fresh state it weighed $11 \frac{1}{2}$ drachms and measured $1 \frac{11}{16} \mathrm{in}$. from above downwards, its antero-posterior diameter was $1 \frac{\pi}{16}$ in. and its oblique diameter from the right in front to the left behind was $1 \frac{3}{4}$ in.

Considerable trouble was experienced in fitting the patient with an effective artificial larynx. A reed instrument tried was far too large to go into the trachea. Many experiments were made with upper tubes with differently shaped openings; finally, the patient himself found that his voice was loudest when a tube was used with two openings, one at the tip and the second larger one on the posterior surface about eight centimetres from the tip.

Kemarks. - The abductor paresis when the patient was first seen was doubtless due to pressure on the right recurrent laryngeal nerve. As to the operation, it was difficult to plan beforehand what one should do, seeing that it was impossible to say where the growth originated. So far as examination by palpation and laryngoscopically could help, it seemed that the growth affected primarily the posterior part of the inner surface of the right thyroid plate. Again, the planning of the operation was rendered a little difficult by some uncertainty about the exact nature of the growth. One knew, as a matter of fact, that a growth had shown itself to be at one part myxo-chondromatous in structure, and therefore when rapidity of growth set in it seemed probable that there was a sarcomatous element in the tumour. Seeing the uncertainty of origin of the growth and also the uncertainty whether it was benign, the decision was made to thoroughly explore the tumour and then to remove it without attempting to do any typical excision of the whole or half larynx, but rather to save as much as possible of the sound framework of the larynx. The recurrent laryngeal nerves were both cut in raising up the cricoid, and for this reason the left arytenoid was removed. The right was of necessity removed with the growth. The thinned cesophageal mucous membrane stretched over the back of the growth was cut. The most interesting features of the case are : (1) the perfection of voice obtained through the vibration of the approximated sides of the brim of the larynx, the voice being more pleasant, louder and more natural than any I have heard produced by the artificial larynx furnished with a reed; (2) the occurrence of so large a laryngeal enchondroma is most rare and possibly unprecedented. The case was shown at a meeting of the Clinioal Society on April 28th, 1893.

Harley street, W.

Society for Relief of Widows and ORPhans OF MEDICAL MEN. - The annual general meeting of this society was held on Friday, May 19th; the President, Sir James Paget, took the chair punctually at 5 o'clock. The secretary read the report for 1892 , from which it appeared that the available receipts had been $£ 326517 s .6 d$., the grants to the widows and orphans $£ 3092$, the expenses $\$ 2473$ s. 10\%, leaving a deficit of $£ 736 s$. A legacy of $£ 20$ had been received, eleven new members had been elected, twelve had died and six had resigned. The number of members at the end of 1892 was 312 . Seven widows had died and three orphans had become ineligible for further grants ; no fresh application for assistance had been received. The seren widows had received $\$ 453710$ s., their husbands having only paid the sum-total of $£ 20314$. as subscriptions. The President announced the great loss the society had sustained by the death of $\mathrm{Mr}$. Fuller, vice-president and treasurer, who as director and acting treasurer had been most zealous and indefatigable in the discharge of his duties and had never lost an opportunity of forwarding the interest of the society. It was suggested that a letter of sympathy and condolence in their sad loss should be sent to the family of the late Mr. Fuller. A vote of thanks to the editors of the medical journals for their great kindness in helping to promote the interests of the society was passed. The following gentlemen were elected directors to fill the vacancies caused by death, resignation and retirement-viz., Mr. Pettifer, Mr. Lenton Heath, Mr. Smith Turner, Mr. Thomas Smith, Dr. Duka, Mr. S. T. Hutchinson, Dr. Martin, Dr. Ryder and Dr. Champneys. A unanimous vote of thanks to the chairman for his kindness in presiding at the meeting closed the proceedings.

\section{A RAPIDLY FATAL CASE OF ANGINA LUDOVICI.}

By E. VALENTINE GIBSON, M.D. Fidis.,

SUPERINTENDENT AND RESIDENT MEDICAL OFFICER, VICTORIA INFIRMARY, GLASGOW.

A MAN aged forty-nine, a moulder, sought advice at the out-patient department of the Victoria Infirmary, Glasgow, on March 6th, 1893, for swelling of the neck. He informed me that his trouble began about noon on the previous day, when he noticed a fulness beneath the lower jaw when he was going to shave. He did not shave, on account of a scab on the right side of the neck below the jaw, which had commenced a few days before as a pimple. During the afternoon and evening the swelling rapidly increased in size, extending up the sides of the neck behind the jaw and on to the chest. During the night he slept but little, feeling " hot and cold by turns," but had no distinct shiverings. He had been a heavy drinker and had been drunk on the evening of the 4th. His previous history was unimportant. On examination there was marked swelling of the tissues beneath the jaw, extending down the neck and front of the chest and upwards behind the angles of the jaws as far as the zygomata. In both these latter situations there were lines of demarcation corresponding to the attachments of the deep cervical fascia, to the rami of the jaws and to the zygomata respectively. The swelling was very marked below the jaw and extended around the neck. There was perceptible enlargement of the salivary glands. No lymphatic glands could be felt. The skin was of normal colour. There was no pitting on pressure and no pain on firm palpation at any part of the swelling, which felt firm and elastic. The floor of the mouth was considerably thickened, but the tongue was not swollen nor raised to any perceptible extent. There was no congestion of the fauces, but there was slight dyspnoea. Just beneath the jaw on the right side there was a scab three quarters of an inch in length and a quarter of an inch in breadth, with a pustular margin, very like a variola pustule, but having no areola. There were no red lines running from it. The circumference around the neck was twenty inches and a half and just below the zygomata twenty-two inches. His temperature was $97.8^{\circ}$. He did not wish to stay in the hospital, as he said he did not feel ill enough; but on my pointing out to him the serious nature of the affection - as I believed the case to be one of angina Ludovici - he consented to become an in-patient. As I had to leave the hospital on business for a few hours I told the house-surgeon to watch him closely. He was admitted to Mr. Maylard's ward at 1 P.M., had his dinner and $a$ bath and went to bed in the side room. Shortly before 3 P.M. he asked the Sister to get him his spectacles as he wished to read. On her return in a few minutes she found him unconscious, lying on his back, his face and lips blue, foam issuing from his mouth, his eyes closed and no air entering his trachea. The house-surgeon (Dr. Logie) was quickly on the spot and performed tracheotomy by two incisions, placing the handle of the scalpel in the trachea, whilst artificial respiration was performed. The patient soon began to breathe violently and the respirations gradually became regular and rhythmical. A large tracheotomy tube was then inserted with some difficulty, as the swelling of the neck was very great. Coming in at 3 o'clock I made an incision in the middle line, from the tip of the chin to the hyoid bone, dividing the structures almost to the floor of the mouth. The wound gaped considerably, and a thin serous discharge came from it, the tissues appearing yellow and gelatinous, but no pus escaped. There was no odour from the discharge. The swelling now extended slightly over the face. The scab below the jaw was remored, and the ulcer, which appeared to be fairly healthy, was thoroughly scraped and antiseptic solutions and dressings were applied. Crepitations could now be felt under the skin of the chest and face. Air was freely entering the trachea. In the next few hours the swelling diminished somewhat in size, but spread further down the chest. The temperature rose in the evening to $101^{\circ}$, and the respiration 
was 32 . At 10 P M. he could swallow very well; respiration had been carried on withont difficulty, and he felt no pain.

- March 7th, 9 A M. - The patient has passed a good night, and there has been no difficulty with the breathing, very little mucus coming throurh the tube. His temperature gradually fell during the night to $98^{\circ}$; pulse 130 , respiration 36 . The gaping wound looks glazed and gelatinous, and a thin inodorous discharge has been escaping in small quantity. "There is no evidence of pus. The ulcer, whicb was scraped, has scabbed over again, but there is now no pustular margin. The swelling has increased in size above the clavicles and has spread further down the chest. There is no pitting of the skin on pressure, and no redness. Fluctuation cannot be made out at any point. There is no congestion of the mucous membrane of the mouth or throat. The patient indicates that he is suffering no pain. Six ounces of urine were drawn off and found to be normal. $11 \mathrm{~A} . \mathrm{M}$.: The patient is becoming very feeble. Although air is freely entering the chest there are dyspnoea and considerable cyanosis of the lips and face. 2.40 P.M. : He is rapidly becoming more livid and the respiration is more rapid. He gradually became comatose and died at 3.15 P.M.

Necropsy, four hours after death, by Dr. Monro, pathologist to the infirmary. - The body was well nourished and was still warm. There was no rigor mortis. The neck was greatly enlarged by a swelling which in the lower part was remarkably firm, so that there was, as it were, a thick rim of indurated tissue over the anterior part of each lateral aspect of the neck, passing back so as to become continuous with the posterior border of the sterno-mastoid. In front of this muscle a well-marked groove was seen corresponding to the deep attachment of the fascia along the posterior border of the ascending ramus of the jaw. The swelling in the upper part of the neck was somewhat looser and was continued over the jaw on to the face, extending as far up as the upper eyelids. From the level of the upper eyelids downwards as far as the level of the nipples emphysema was distinctly appreciable. The head and neck were so firmly fixed-doubtless by the swelling described-that movements both antero-posteriorly and laterally were very limited. The neck itself was swollen at the back and the soft tissues over each shoulder were so much swollen that a distinct groove extended all round the base of the neck. There was nowhere pitting on pressure of the affected parts. A tracheotomy wound was present just below the cricoid and another incision extended from the skin to the hyoid bone. On dividing the soft structures on the front of the chest-wall the subcutaneous tissue presented, especially in its deeper part, a somewhat glistening appearance, which seemed to be due partly to minute bubbles of gas and partly to a gelatinous condition of the connective tissue. This contained a good deal of fluid, but even after pressing the fluid out of some of the tissue the jelly-like material was to some extent preserved, and it was found on section that this whitish appearance due to bubbles of gas, extended as far as the nipples, whilst the gelatinous condition was present for some inches further down. There was no redness or discolouration of the skin except where a slight crust covered a small reddish ulcer measuring three-quarters of an inch by one-quarter of an inch, about an inch below the jaw on the right side. The anterior mediastinal fatty tissue was greatlyswollen, with the peculiar cdema before described, and as it was cut air bubbles rose to the surface; the swelling was particularly apparent in the upper parts. There was nothing worthy of special notice in the heart; the left lung was slightly adherent posteriorly. The bronchial tubes contained blood-stained, frothy fluid and the large pulmonary vessels were engorged with blood. The organ itself was very emphysematous, especially at its upper part and free margins. At the part posteriorly corresponding to the adhesion there was a pale area on the surface of the lung, measuring three inches vertically and two inches transversely. On section this area was found to be the base of a wedge-shaped mass of lung tissue one inch and three-quarters in depth. The base of the lung was congested and cedematous and presented appearances resembling infarctions of snaller size and not so entirely pale as the one already described. Over the anterolateral aspect of the upper lobe of the right lung there was a circular area three inches or more in diameter, mostly dark in colour, but with the central portion pale; the pale portion was here seen to be also wedge-shaped or pyramidal in form. The rest of the lung was emphysematous, but not extremely congested. The cedematous swelling, already described in connexion with the anterior mediastinum, was found after removal of the lung to involve the connective tissue of the poster ior mediastinum also. The salivary glands appeared to be normal, although imbedded in gelatinous tissue. The tongue was not enlarged. The mucous membrane of the right bronchus was somewhat congested. There was well-marked cedema glottidis, the cedematous tissue partly resembling that found elsewhere, though perhaps not quite so firm. There was no evidence of the odema of the connective tissue extending below the diaphragm. The spleen weighed six ounces and was somewhat soft. The kidneys were congested and contained a few small cysts. The capsules were difficult to strip off, but there were no granulations. A certain quantity of the fluid from the cedematous tissue was kept for examination, but no organism could be found. A portion of the subcutaneous tissue of the chest wall was examined and showed in parts great numbers of leucocytes, some with single but the majority with multiple nuclei. The piece of skin covered with scab was also examined and was found to be infiltrated, particularly at its deeper parts, with round cells. These were, however, much more abundant in the underlying subcutaneous tissue.

A bacteriological examination of specimens from this case, including the scab on the neck, has been made by Dr. J. Wilson Cameron at the Royal Infirmary Laboratory, but no specific pathogenic organisms have been discovered.

Remarks. - This case practically agrees with all Dr. Lud. wig's diagnostic points given by Mr. Parker in THE LANCET, Oct. 25th, 1879-viz., (1) "The slight inflammation which even when it exists disappears after a day or two and which if it persists may be looked upon as symptomatic." There was never at any time congestion of the throat. (2) "The peculiar wood-like induration of the connective tissue, which will not receive impressions." The connective tissue differed from the brawny feel of the indurated tissue of commencing cellulitis, feeling more as if there were a solid jelly.like material underneath. This condition was modified some what after the tracheotomy, owing to the emphysema There was never any pitting on pressure of the affected tissue. (3) "The uniform spread of this induration, so that it is always sharply bounded by a border of entirely unaffected cellular tissue." The disease spread uniformly, but was only at first bounded sharply at the attachment of the fascia to the zygomata and rami of the jaws, spreading later over the chin on to the face, though not extending above the upper eyelids. There was no sharp line of demarcation along the front of the chest, the disease gradually fading away into healthy tissue. (4) "The hard swelling under the tongue with a bolster-like swelling along the interior of the lower jaw, of deep red or bluish-red colour." The fioor of the mouth was considerably thickened, but there was no congestion of the mucous membrane. (5) "The escape of the glands, although the disease attacks their cellular tissue surroundings, or may even commence in it." None of the salivary glands were enlarged, and they all appeared to be normal in size and colour, although they were embedded in the gelatinous tissue. The points of especial interest in the case are: (1) The suddenness of the onset and the rapidly fatal termination-forty-one hours after the first symptom was noticed. (2) Was the small ulcer under the jaw the originating point of the disease? The swelling was not more marked around that point than elsewhere, nor was there any sign as if the disease were further advanced at that spot. At this point one would have expected, if this had been the focus of the disease, that there would have been evidence of greater local disturbance, or at least that the ulcer would have looked markedly unhealthy. (3) The low temperature $\left(978^{\circ}\right)$ that existed on admission, although the disease must have been rapidly spreading. (4) The entire absence both of pain over any part of the swelling on palpation and of any great discomfort until the respiration was seriously interfered with. (5) Absence of gangrene of the tissues or even redness of the skin and the entire absence of pus. This, no doubt, would be accounted for by the early death of the patient-which seems to have been caused by pulmonary infarctions, the symptoms a few hours before death pointing to that condition,- - the disease not having lasted long enough to have caused gangrene. Early intubation and numerous free incisions seem to be the course of treatment indicated by the experience of this case. If intubation of the larynx had been performed immediately on admission the extensive emphysema which followed the performance of tracheotomy would have been avoided.

I am indebted to Mr. Maylard for permission to report this case.

Victoria Infirmary, Glasgow. 


\section{COMPOUND COMMINUTED FRACTURE OF THE SKULL :}

WTTH EXTENSIVE LOSS OF OSSEOUS COVERING TO THE BRAIN ; RECOVERY.

BY H. A. LEDIARD, M.D. Edin., F.R.C.S. ENG., SURGEON TO THE CUMBERLAND INFIRMARY.

ON the night of Dec. 20th, 1892, a carter aged twenty-four was brought to the Cumberland Infirmary suffering from a severe injury to the head. It appeared that he was returning on an empty lorry with two other men and that, when sitting in the front part of the waggon, he probably fell off whilst asleep and was run over, for his companions suddenly missing him retraced their steps for about a mile and found him on the road unconscious and bleeding from a wound on the right side of the head. He was placed by them on the waggon and bronght into the hospital, a distance of twelve miles. On admission to the infirmary Mr. Mathews, the house surgeon, found the patient to be unconscious and breathing stertorously; the scalp was reflected from the greater part of the right side of the head and was hanging over the

Fig. 1.

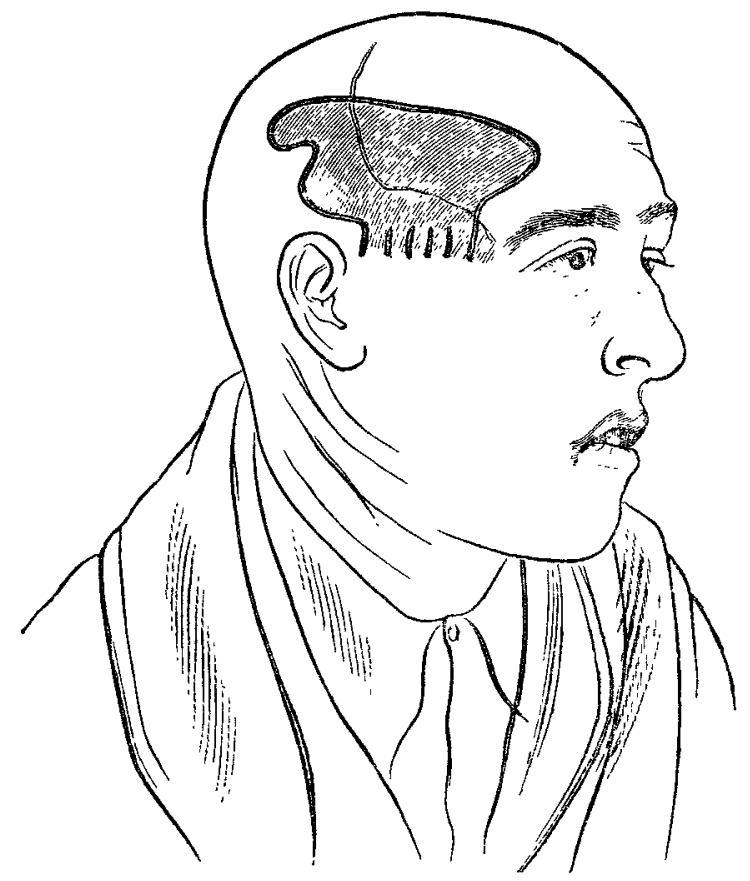

right ear and face; the bone was seen to be broken up intolarge plates, which were partly loose and tilted out of position and evidence of extensive hæmorrhage was present. Both eyes were ecchymosed and the lids swollen and there was bleeding from both nostrils. The injuries were, however, limited to the head. It was found needful to administer a little chloroform to restrain unconscious movements, and it was then seen that the soft parts were laid open from near the vertex towards the angle of the right orbit, as shown by the cicatricial line which crosses the shaded area in Fig. 1. The condition seemed so hopeless and the fracture so extensive that I almost hesitated to touch the patient; but on removing one bit of bone after another and finding that the dura mater was uninjured, there was more encouragement given to make the best of the case. The bone removed corresponded to the area shown on the engraving by the dark shade, and it will be seen that portions of the temporal, parietal and frontal bones were included in the injury. From the site of fracture the fissures extended in all directions towards the orbital plate on the right side, the base of the skull in the temporal region and backwards towards the occipital bone. All blood which had accumulated between the vault and the dura mater was syringed out, and after inserting a large horsehair drain the scalp was stitched up and the patient removed to bed. A blue appearance of the dura mater within the area of fracture was suggestive of subdural hæmorrhage, but no symptoms of cortical lesion appeared. For three days the man was in a drowsy condition with a slow pulse $(60)$ and passing urine involuntarily. In ten days, however, the wound healed, power was recovered over the bladder, he ate and slept and expressed himself as feeling quite well. The brain was seen to pulsate over a large area and, with the exception of a drooping of the right eyebrow and a smoothing of the wrinkles on the right forehead no trace of paralysis appeared. The patient was discharged on March 2nd after being provided with a protection of leather and metal for the right side of the head. It is to be observed that the hearing when tested was nearly as good on the right side as on the left. The engravings, which are from photographs taken in the ward, show the area of brain uncovered by bone, a pencil mark on the skin having previously defined the edge of the bone. The four vertical lines seen in Fig. 1 indicate the disappearance of the uncovered surface of brain behind the zygoma. The engraver has accurately represented the paralysis of the right occipito-frontalis muscle in Fig. 2. The broken fragments when fixed together measured eleven centimetres long by six centimetres broad but the actual aperture in the man's head was probably somewhat larger, as all sharp points and edges were smoothed away with pliers. I have had many head injuries under observation, but the present one strikes me as exceptionally remarkable on account of the great destruction of bone without injury to the dura mater, and

FIG. 2.

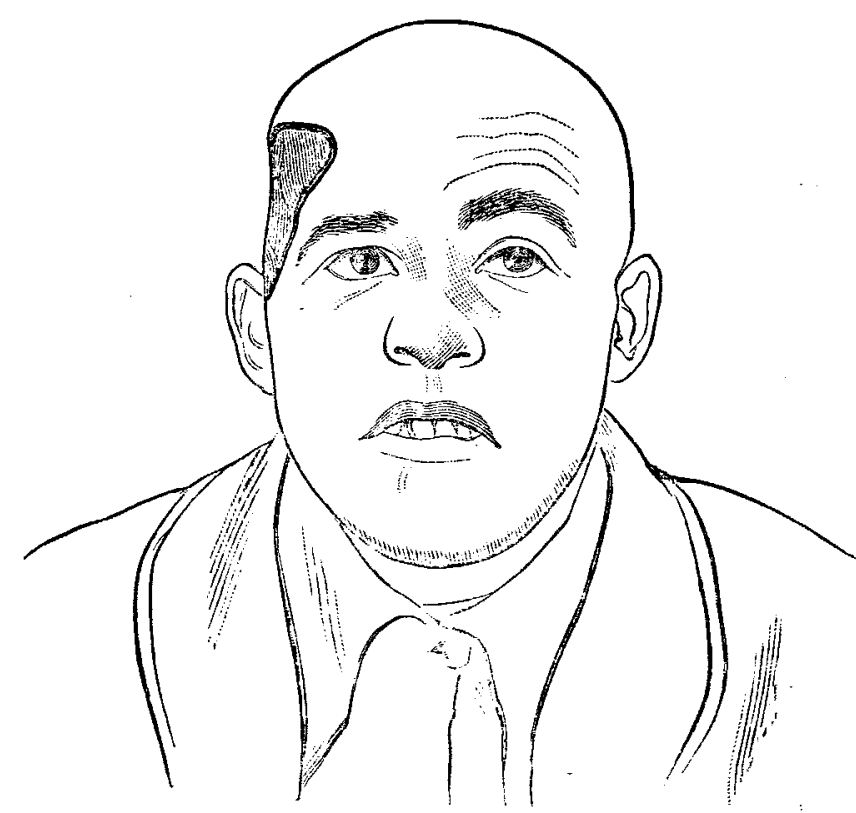

herein, no doubt, lay the reason why the man made so good a recovery. Doubtless larger spaces have been bared by the trephine for operative procedure on the brain without harm resulting, but these circumstances are wholly different from the rude violence of a cartwheel. As regards temperature, the highest point reached was $103^{\circ} \mathrm{F}$. two days after the accident, and then there was an almost immediate fall to about normal.

Lowther-street, Carlisle.

The Surgical Aid Society.-The promoters of this society have recently resolved to extend its operations by the formation of branches in various provincial towns, and the citizens of Manchester have in public meeting expressed their wish to participate in the benefits of such an auxiliary. The mayor is to act as president and the eommittee will be composed of gentlemen of bigh standing in the city.

Nottingham Children's Hospital.-The annual meeting of the friends of this institution was held on the 18th ult., and a very favourable report was presented withregard to its pecuniary resources and the amount of good work accomplished by its means. The number of patients cured or relieved during 1892 was larger than in any previous. year, whilst the income of the charity was steadily increasing. Six cots are now supported by special donations, and two of them have now been endowed. A resolution was moved and carried that the Duchess of Portland be asked to act as president during the ensuing year. 